\title{
ConTRole De Brachiaria brizantha, COM Uso do GlyPHOSATE, NA FoRMAÇÃo de Pastagem de TifTON 85 (Cynodon spp.) ${ }^{1}$
}

\author{
Brachiaria brizantha Control Using Glyphosatefor Tifton 85 (Cynodon spp.) Pasture Formation
}

\author{
SANTOS, M.V. ${ }^{2}$, FERREIRA, F.A. ${ }^{3}$, FREITAS, F.C.L. ${ }^{4}$, TUFFI SANTOS, L.D. ${ }^{5}$, VIANA, J.M. ${ }^{6}$, \\ ROCHA, D.C.C. ${ }^{2}$ e FIALHO, C.M.T. ${ }^{7}$
}

\begin{abstract}
RESUMO - Este trabalho foi proposto com o objetivo de avaliar a eficiência do herbicida glyphosate no controle de Brachiaria brizantha, cultivar Marandu, na formação de pastagem de Tifton 85. O experimento foi realizado em ambiente desprotegido, utilizando vasos de polietileno com capacidade de $10 \mathrm{~L}$. Os tratamentos constituíram-se de duas épocas de aplicação e oito doses: 0, 90, 180, 360, 720, 1.080, 1.440 e 1.800 g e.a. ha ${ }^{-1}$ de glyphosate, no esquema fatorial $2 \times 8$. O delineamento experimental foi em blocos casualizados, com quatro repetições. Cada parcela foi constituída de um vaso com duas plantas de B. brizantha e duas de Tifton 85. A primeira aplicação do glyphosate foi realizada antes do perfilhamento das plantas de $B$. brizantha, quando estas apresentavam cerca $10 \mathrm{~cm}$ de altura, e a segunda, quando as plantas estavam com quatro a cinco perfilhos e aproximadamente $20 \mathrm{~cm}$ de altura. Para cada época de aplicação foram realizadas avaliações visuais de controle de $B$. brizantha e intoxicação nas plantas de Tifton 85, aos 15, 30 e 60 DAA (dias após aplicação). Aos 60 DAA, as plantas de ambas as espécies forrageiras foram cortadas e secas em estufa, assim como a rebrota aos 60 DAC (dias após o corte). Porcentagem de controle de $90 \%$ de $B$. brizantha, aos 60 DAA, foi obtida com 133,60 $\mathrm{g} \mathrm{ha}^{-1}$ na primeira aplicação e 365,63 $\mathrm{g} \mathrm{ha}^{-1}$ na segunda. Foi observado aos $60 \mathrm{DAA}$, na primeira e segunda épocas de aplicação, que baixas doses de glyphosate $\left(133,60\right.$ e $365,63 \mathrm{~g}^{\text {ha }}{ }^{-1}$, respectivamente) promovem controle da braquiária, com ausência de rebrota dessas plantas aos 60 DAC, e intoxicação leve de Tifton 85, sem influenciar o rendimento desta forrageira. Devido à maior tolerância do Tifton 85 ao glyphosate, é possivel o controle de Brachiaria brizantha utilizando doses baixas de glyphosate, sem, no entanto, comprometer o rendimento forrageiro de Tifton 85.
\end{abstract}

Palavras-chave: braquiária, herbicida, controle químico, tolerância.

ABSTRACT - This study aimed to evaluate glyphosate efficiency in the control of Brachiaria brizantha, $c v$ marandu, for Tifton-85 pasture formation. The experiment was carried out in the field in $10 L$ capacity polyethylene pots, and arranged in a randomized block design, in a $2 \times 8$ factorial scheme, with two application times, eight glyphosate rates 10;90, 180; 360; 720; 1,080; 1,440; and 1,800 g e.a. $\mathrm{ha}^{-1}$ ), and four replicates. Each plot had a vase with two B. brizantha $c v$. Marandu and two Tifton 85 plants. The first application time was before B. brizantha plant tillering, when the plants were $10 \mathrm{~cm}$ high and the second one, when B. brizantha was around $20 \mathrm{~cm}$ high and showed four or five tillers. For each application time, visual evaluations of $\boldsymbol{B}$. brizantha control and intoxication in the Tifton 85 plants were conducted at 15, 30 and 60 DAA (days of application). At 60 DAA, the plants were cut and dried in a greenhouse, and sprouts were evaluated at 60 DAC days after cut. Control percentage of $90 \%$ of B. Brizantha, at $60 \mathrm{DAA}$, was obtained with $133.60 \mathrm{~g} \mathrm{ha}^{-1}$ in the first application and $365.63 \mathrm{~g} \mathrm{ha}^{-1}$ in the second. At $60 \mathrm{DAA}$ after the first and second application, respectively, low dosages of glyphosate (133.60 and $365.63 \mathrm{~g} \mathrm{ha}^{-1}$ ), were observed to promote B. brizantha control with absence of sprouts at $60 \mathrm{DAC}$, and mild intoxication of Tifton 85 without influencing its yield. Due to the higher tolerance of Tifton 85 to glyphosate, it is possible to control B. brizantha by using low doses of glyphosate, without compromising Tifton 85 forage yield.

Keywords: Brachiaria brizantha, herbicide, chemical control, tolerance.

Recebido para publicação em 2.5.2006 e na forma revisada em 27.2.2007.

2 Doutoranda em Zootecnia, Dep. de Zootecnia, Universidade Federal de Viçosa - DZO/UFV, 36570-000 Viçosa-MG, $<$ marciavitori@hotmail.com $>;{ }^{3}$ Prof. Titular - DFT/UFV; ${ }^{4}$ Prof. de Fitotecnia da Universidade Federal Rural do Semi-Árido/ UFERSA $;{ }^{5}$ Pós-Doutorando em Fitotecnia - DFT/UFV; ${ }^{6}$ Mestrado em Zootecnia - DZO/UFV; ${ }^{7}$ Aluno de Agronomia - UFV. 


\section{INTRODUÇÃO}

A eficiência da pecuária brasileira nos últimos anos relaciona-se principalmente à utilização das gramíneas forrageiras como principal recurso a ser explorado para alimentação dos rebanhos. Entretanto, um dos principais fatores responsáveis pelos baixos indices de produtividade da pecuária nacional é a estacionalidade da produção de forragens, visto que os niveis de produção animal obtidos na estação das águas são comprometidos pelo baixo rendimento forrageiro durante o periodo das secas (Pereira, 2000).

O Brasil tem grande potencial de exploração da pecuária a pasto, sendo crescente o interesse por programas que visem a integração do manejo da pastagem e conservação de forragem, nas formas de feno e silagem.

Dentre as espécies forrageiras utilizadas para produção de feno e para o pastejo, destacam-se as do gênero Cynodon, popularmente conhecidas como gramas-bermuda e estrelas. Nesse grupo, vários cultivares estão disponiveis no mercado, como o Coastcross [C. dactylon cv. Coastal X C. nlemfuensis var. robustus], Florico (C. nlemfuensis var. nlemfuensis), Florona (C. nlemfuensis var. nlemfuensis) e Tifton 85 (Cynodon spp.) (Oliveira et al., 2000; Alves et al., 2001; Gonçalves et al., 2003; Rocha et al., 2001; Rovetta et al., 2001; Alvim et al., 2003; Belluzzo et al., 2002; Rosa et al., 2002).

O cultivar Tifton 85 foi desenvolvido por Burton et al. (1993). Essa forrageira é um híbrido F1 entre a introdução Sul-Africana, registro P1 290884 (Cynodon dactylon) e Tifton 68 (Cynodon nlenfüensis). É um cultivar perene, de porte mais alto, com colmos mais compridos, folhas mais largas e cor verdeescura, rizomas grandes e em menor número, e estolões que se expandem rapidamente (Burton et al., 1993), sendo selecionado pela alta produtividade e digestibilidade, quando comparado com a maioria das bermudas híbridas (Pedreira, 1996). Multiplica-se através de mudas enraizadas ou estolões, possuindo exigência média a alta em fertilidade, que são con siderados os fatores limitantes na formação dessas forrageiras; tem bom desenvolvimento em regiões tropicais e subtropicais
(Burton et al., 1993; Pedreira, 1996; Hill et al., 1993, Evangelista, 2005). É recomendado para fenação e para pastejo em decorrência da boa relação folha/colmo que possui, com boa aceitabilidade por bovinos, eqüinos, ovinos e caprinos.

Algumas espécies do gênero Brachiaria, como $B$. brizantha e $B$. decumbens, possuem ampla adaptação edafoclimática e fácil disseminação devido à grande quantidade de sementes produzidas e à dormência destas, facilitando a sua dispersão ao longo do tempo. Embora consideradas excelentes forrageiras, essas espécies não possuem boa aceitabilidade por parte de eqüinos e muares e, também, podem ser indesejáveis em áreas de cultivos agrícolas ou naquelas destinadas à produção de forragem para pastejo, ensilagem ou fenação com outras espécies menos competitivas.

A vantagem competitiva de $B$. brizanthaem relação a Tifton 85 é esperada, devido, principalmente, ao diferente padrão de crescimento dessas duas espécies. B. brizantha possui porte mais ereto, podendo atingir mais de $1,5 \mathrm{~m}$ de altura (Lorenzi, 2002). Já o Tifton 85 possui porte mais baixo, com crescimento horizontal em relação ao nivel do solo. Nessas condições, ao ser sombreado pelas plantas de $B$. brizantha, o Tifton 85, por ser uma planta de metabolismo $\mathrm{C}_{4}$ de fixação de $\mathrm{CO}_{2}$, tem seu potencial de crescimento e desenvolvimento limitado, resultando em menor produtividade. Em razão dessa interferência, torna-se fundamental o controle das plantas de braquiária em áreas de cultivo de Tifton 85.

A implantação de pastagem de espécies de propagação vegetativa, como o Tifton, em áreas com alta infestação de gramíneas de propagação seminífera, como as braquiárias, não é tarefa muito fácil, devido à competição exercida por essas espécies e à falta de herbicidas seletivos, com efeito graminicida. Entretanto, espécies de propagação vegetativa possuem tecido de reserva e, normalmente, toleram doses mais elevadas de herbicidas que as plantas jovens originadas de sementes. Além disso, segundo Silva et al. (2006), algumas gramineas são mais tolerantes a herbicidas do que outras, sendo isso uma ferramenta importante no manejo de espécies daninhas em culturas com maior grau de tolerância. 
Foi verificado, em ensaios preliminares, que o Tifton 85 tolera doses mais elevadas do glyphosate em relação às plantas de Brachiaria brizantha, o que leva à hipótese do uso desse herbicida para o controle de Brachiaria brizantha em pastagem de Tifton 85.

Assim, avaliou-se a eficiência do glyphosate no controle de $B$. brizantha, cultivar Marandu, na formação de pastagem de Tifton 85 .

\section{MATERIAL E MÉTODOS}

O ensaio foi conduzido em ambiente desprotegido, no campus da Universidade Federal de Viçosa, em Viçosa-MG, localizada a $20^{\circ} 45^{\prime}$ de latitude sul, $46^{\circ} 51^{\prime}$ de longitude oeste e 689 metros de altitude, entre os meses de dezembro de 2004 e maio de 2005.

Os tratamentos constituíram-se de duas épocas de aplicação e sete doses: $0,90,180$, $360,720,1.080,1.440$ oito 1.800 g e.a. ha ${ }^{-1}$ de glyphosate, no esquema fatorial $2 \times 8$. O delineamento experimental utilizado foi em blocos casualizados, com quatro repetições. Cada parcela foi constituída de um vaso de fundo perfurado, contendo $10 \mathrm{~L}$ de solo (Latossolo Vermelho-Amarelo, LVA), previamente adubado com $5 \mathrm{~kg}$ de superfosfato simples por $\mathrm{m}^{3}$, com duas plantas de Brachiaria brizantha cultivar Marandu e duas plantas de Tifton 85 . Os vasos foram mantidos em ambiente desprotegido. As plantas de Tifton 85 foram provenientes de estolões padronizados por tamanho e peso e transplantadas nos vasos. B. brizantha foi semeada em bandejas de polipropileno, na profundidade de $1 \mathrm{~cm}$, sendo transplantadas, 20 dias após emergência, duas plântulas por vaso, intercaladas às duas plantas de Tifton 85. As irrigações foram feitas diariamente, mantendo-se o solo próximo a $80 \%$ da capacidade de campo. A cada 14 dias foram efetuadas adubações em cobertura com $3 \mathrm{~g}$ da fórmula N-P-K (20-05-20) por vaso. As demais plantas que ocorreram nos vasos foram eliminadas manualmente, buscando, assim, observar o efeito dos tratamentos apenas nas duas espécies estudadas.

No momento da aplicação a temperatura do ar se encontrava a $23^{\circ} \mathrm{C}$, com umidade relativa de $80 \%$ e velocidade do vento de
4,0 $\mathrm{km} \mathrm{h}^{-1}$. A aplicação foi feita com auxilio de um pulverizador costal, munido com barra de dois bicos de jato plano ("leque") XR 11002 , espaçados entre si de $0,5 \mathrm{~m}$, à pressão constante de $210 \mathrm{kPa}$, aplicando um volume de calda equivalente a $180 \mathrm{~L} \mathrm{ha}^{-1}$, em duas épocas, considerando o desenvolvimento das plantas de $B$. brizantha como referencial. A primeira época de aplicação ocorreu no final de dezembro de 2004 e foi realizada antes do perfilhamento das plantas de $B$. brizantha, momento em que apresentavam cerca de $10 \mathrm{~cm}$ de altura; a segunda aplicaçao foi realizada no final de janeiro de 2005, com cerca de quatro a cinco perfilhos por planta e aproximadamente $20 \mathrm{~cm}$ de altura. O produto comercial utilizado foi o Roundup original, na concentração de $360 \mathrm{~g} \mathrm{~L}^{-1}$ de glyphosate.

Foram realizadas avaliações de controle das plantas de $B$. brizantha e nível de intoxicação das plantas de Tifton 85 , aos 15,30 e 60 DAA, por meio de observações visuais, utilizando-se a escala de 0 a 100 , sendo 0 a ausência de controle ou intoxicação e 100 o controle total da espécie ou morte das plantas, respectivamente para $B$. brizantha e Tifton 85 .

As plantas de ambas as espécies foram cortadas ao nivel do solo aos 60 DAA, separadas e secas em estufa de renovação forçada de ar a $60-70{ }^{\circ} \mathrm{C}$, até peso constante. Após o corte das plantas, o solo dos vasos foram adubados e irrigados, a fim de proporcionar condições ideais para rebrota das plantas. Aos 60 DAC, avaliou-se a capacidade de rebrota, realizando outro corte e secagem da parte aérea das plantas de B. brizantha e Tifton 85 .

Os resultados foram submetidos à análise de variância pelo teste $\mathrm{F}$ a $5 \%$ de probabilidade. Posteriormente, os dados referentes ao controle de $B$. brizantha e à intoxicação de Tifton 85 foram submetidos a análise de regressão; na escolha dos modelos, levou-se em conta a explicação biológica, o R2 e a significância dos parâmetros. Para os dados de matéria seca, foi feita comparação entre médias, para as duas espécies avaliadas, através do teste de Tukey a $5 \%$ de probabilidade. Os dados foram analisados com auxílio dos programas computacionais Sigmaplot e GENES. 


\section{RESULTADOS E DISCUSSÃO}

A ação do glyphosate no controle de $B$. brizantha e na intoxicação das plantas de Tifton 85 foi influenciada pelas doses utilizadas $(\mathrm{P}<0,05)$, na primeira e segunda épocas de aplicação do herbicida, tanto na aplicação sobre as plantas antes do perfilhamento como nas plantas com quatro a cinco perfilhos.

Quando a aplicação do herbicida foi realizada antes que as plantas perfilhassem, o controle de braquiária superior a $90 \%$ foi observado a partir da concentração de $1.068,75 \mathrm{~g} \mathrm{ha}^{-1}$ aos $15 \mathrm{DAA} ; 175,78 \mathrm{~g} \mathrm{~L} \mathrm{ha}^{-1}$ aos 30 DAA; e $133,60 \mathrm{~g} \mathrm{ha}^{-1}$ aos 60 DAA (Figura 1). Verifica-se, na Figura 1, que o efeito do glyphosate sobre $B$. brizantha foi lento, mostrando-se eficiente a partir de 30 DAA.

Os niveis de intoxicação nas plantas de Tifton 85 , em relação às doses que proporcionaram controle eficiente de $B$. brizantha aos 30 e 60 DAA, para a primeira época de aplicação, foram, respectivamente, de 13,60\%, referente à dose de $175,78 \mathrm{~g} \mathrm{~L} \mathrm{ha}^{-1}$; e $1,21 \%$, referente à dose de 133,60 $\mathrm{g}^{\text {ha }}{ }^{-1}$. Esses valores são relativamente baixos, evidenciando a maior sensibilidade das plantas de $B$. brizantha ao herbicida glyphosate, quando em comparação com as plantas de Tifton 85 (Figuras 1 e 2). A Figura 5 ilustra a produção de matéria verde de $B$. brizantha até $90 \mathrm{~g} \mathrm{ha}^{-1}$ do glyphosate e de Tifton 85 até $1.080 \mathrm{~g} \mathrm{ha}^{-1}$, aos 60 DAA.

$\mathrm{Na}$ primeira época de aplicação, verificouse para a massa seca da parte aérea, aos 60 DAA, decréscimo na produção de forragem de Tifton 85 nas doses superiores a $720 \mathrm{~g}^{\text {ha }}{ }^{-1}$ do glyphosate, quando em comparação à testemunha sem herbicida. Aos 60 DAC, observou-se ausência de rebrota de plantas de B. brizantha a partir de $180 \mathrm{~g} \mathrm{ha}^{-1}$ (Tabela 1), confirmando o controle que fora observado a partir da concentração de 133,60 g ha-1 (Figura 1). Essa eficiência no controle resultou em maior produção de massa seca de Tifton 85 para as doses entre 180 e $720 \mathrm{~g} \mathrm{ha}^{-1}$, devido à eliminação da competição promovida por $B$. brizantha. No entanto, doses superiores a $720 \mathrm{~g} \mathrm{ha}^{-1}$ promoveram redução de massa seca de Tifton 85 devido à intoxicação causada pelo herbicida, inibindo a rebrota nas doses mais altas. A partir da concentração de $1.440 \mathrm{~g} \mathrm{ha}^{-1}$, observa-se ausência de brotações das plantas de Tifton (Tabela 1).

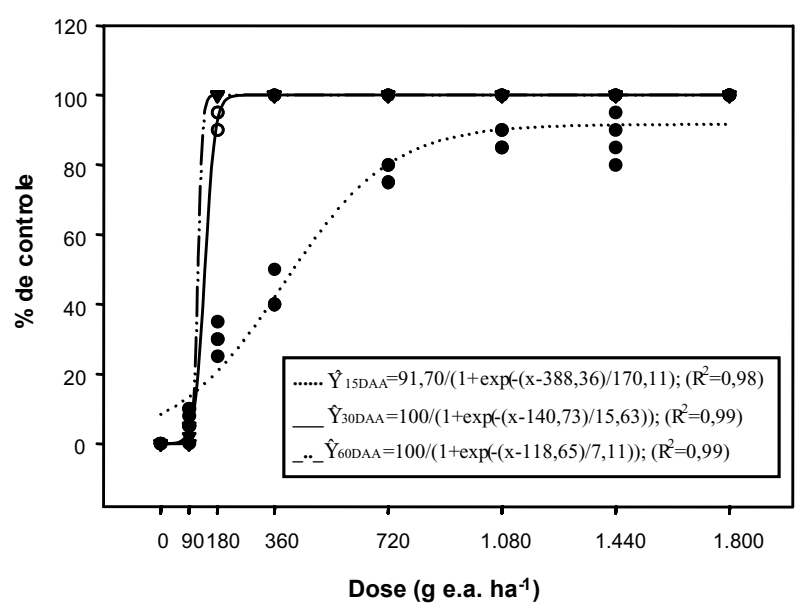

Figura 1 - Porcentagem de controle de Brachiaria brizantha aos 15, 30 e 60 dias após a aplicação (DAA), em função das doses de glyphosate aplicado sobre plantas dessa espécie antes do perfilhamento (primeira época de aplicação).

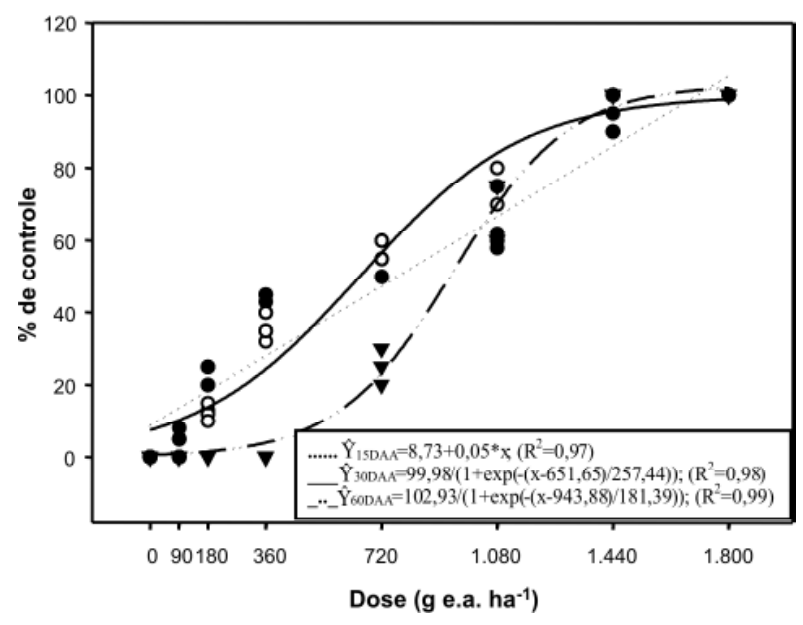

Figura 2 - Porcentagem de intoxicação de Cynodon spp. (Tifton 85 ) aos 15, 30 e 60 dias após a aplicação (DAA), em função das doses de glyphosate aplicado sobre plantas de Brachiaria brizantha antes do perfilhamento (primeira época de aplicação).

Quando a aplicação foi realizada em plantas nos estádios de quatro a cinco perfilhos, observou-se controle de $B$. brizantha superior a $90 \%$ a partir das doses de $534,38 \mathrm{~L} \mathrm{ha}^{-1}$ aos 30 DAA e $365,63 \mathrm{~L} \mathrm{ha}^{-1}$ aos 60 DAA (Figura 3). Nessa situação, os niveis de intoxicação das plantas de Tifton 85 foram, respectivamente, de 9,55 e 0,71\%, considerados baixos (Figura 4). Esses resultados indicam 
Tabela 1 - Massa seca de Cynodon spp. (Tifton 85) e Brachiaria brizantha, submetidas às doses de 0, 90, 180, 360, 720, $1.080,1.440$ e $1.800 \mathrm{~g}$ e.a. ha $^{-1}$ do glyphosate, aos 60 dias após aplicação (DAA) e na rebrota aos 60 dias após o corte (DAC), para a primeira época de aplicação (antes do perfilhamento de Brachiaria brizantha)

\begin{tabular}{|c|c|c|c|c|}
\hline \multirow{3}{*}{$\begin{array}{c}\left.\text { Dose (g e.a. ha }{ }^{-1}\right) \\
\text { Glyphosate }\end{array}$} & \multicolumn{2}{|c|}{60 DAA } & \multicolumn{2}{|c|}{$60 \mathrm{DAC}$} \\
\hline & Tifton 85 & Brachiaria brizantha & Tifton 85 & Brachiaria brizantha \\
\hline & \multicolumn{2}{|c|}{ Massa Seca (g por vaso) } & \multicolumn{2}{|c|}{ Massa (g por vaso) } \\
\hline Testemunha & $114,475 \mathrm{a}$ & $10,075 \mathrm{~b}$ & $46,825 \mathrm{ab}$ & $20,10 \mathrm{a}$ \\
\hline 90 & $96,2 \mathrm{a}$ & $16,025 \mathrm{a}$ & $35,875 \mathrm{bc}$ & $22,42 \mathrm{a}$ \\
\hline 180 & $109,975 \mathrm{a}$ & $0,0 \mathrm{c}$ & $57,6 \mathrm{ab}$ & $0,0 \mathrm{~b}$ \\
\hline 360 & $90,5 \mathrm{a}$ & $0,0 \mathrm{c}$ & $64,15 \mathrm{a}$ & $0,0 \mathrm{~b}$ \\
\hline 720 & $33,15 \mathrm{~b}$ & $0,0 \mathrm{c}$ & $49,05 \mathrm{ab}$ & $0,0 \mathrm{~b}$ \\
\hline 1.080 & $10,35 \mathrm{bc}$ & $0,0 \mathrm{c}$ & $21,70 \mathrm{~cd}$ & $0,0 \mathrm{~b}$ \\
\hline 1.440 & $0,0 \mathrm{c}$ & $0,0 \mathrm{c}$ & $0,0 \mathrm{~d}$ & $0,0 \mathrm{~b}$ \\
\hline 1.800 & $0,0 \mathrm{c}$ & $0,0 \mathrm{c}$ & $0,0 \mathrm{~d}$ & $0,0 \mathrm{~b}$ \\
\hline CV $(\%)$ & 20,02 & 63,71 & 28,33 & 70,68 \\
\hline
\end{tabular}

Médias seguidas pelas mesmas letras nas colunas não diferem entre si pelo teste de Tukey a 5\% de probabilidade.

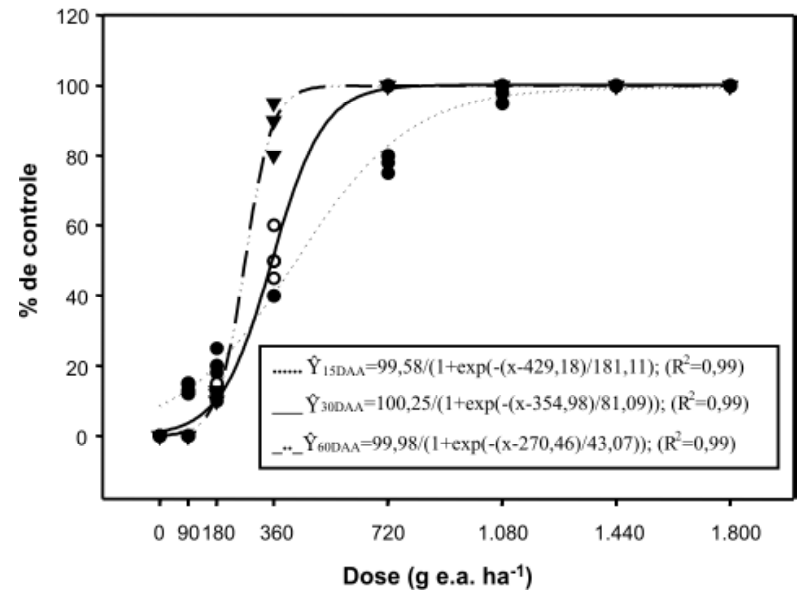

Figura 3 - Porcentagem de controle de Brachiaria brizantha aos 15, 30 e 60 dias após a aplicação (DAA), em função das doses de glyphosate aplicado sobre plantas de Brachiaria brizantha com quatro a cinco perfilhos/planta (segunda época de aplicação).

que $B$. brizantha possui maior sensibilidade ao glyphosate, quando em comparação com as plantas de Tifton 85 (Figuras 3 e 4), mesmo em plantas mais desenvolvidas, após o perfilhamento.

Em plantas de $B$. brizantha com quatro a cinco perfilhos, a dose de glyphosate requerida para controle desta espécie foi maior que aquela aplicada antes do perfilhamento.

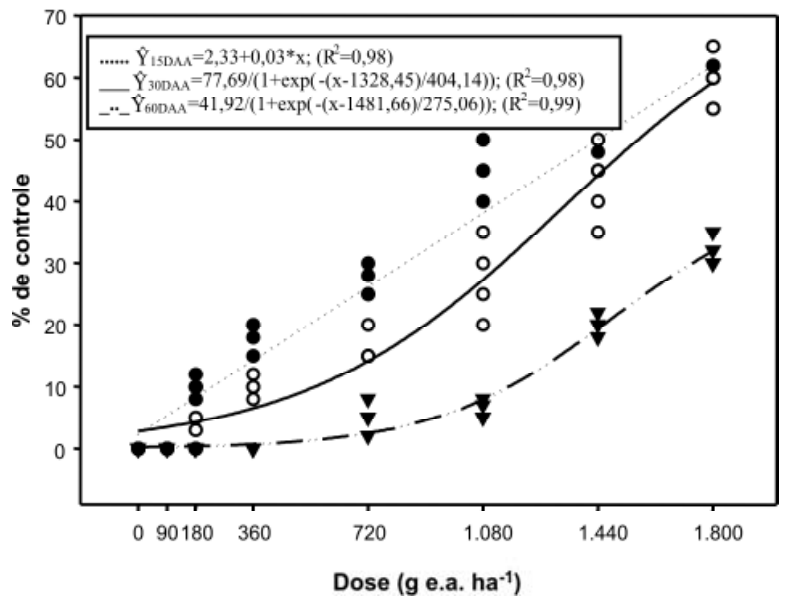

Figura 4 - Porcentagem de intoxicação de Cynodonspp. (Tifton 85 ) aos 15,30 e 60 dias após a aplicação (DAA), em função das doses de glyphosate aplicado sobre plantas de Brachiaria brizantha com quatro a cinco perfilhos/planta (segunda época de aplicação).

Comportamento semelhante foi observado para a tolerância do Tifton 85, com o aumento da idade da planta, devido ao maior acúmulo de reservas, o que está de acordo com Silva et al. (2003), os quais relatam que a dose de herbicidas a ser aplicada varia em função da espécie e com a idade da planta. Esses resultados indicam que, quanto mais jovens se encontrarem as plantas de $B$. brizantha, menor o gasto com herbicida para o seu controle. 


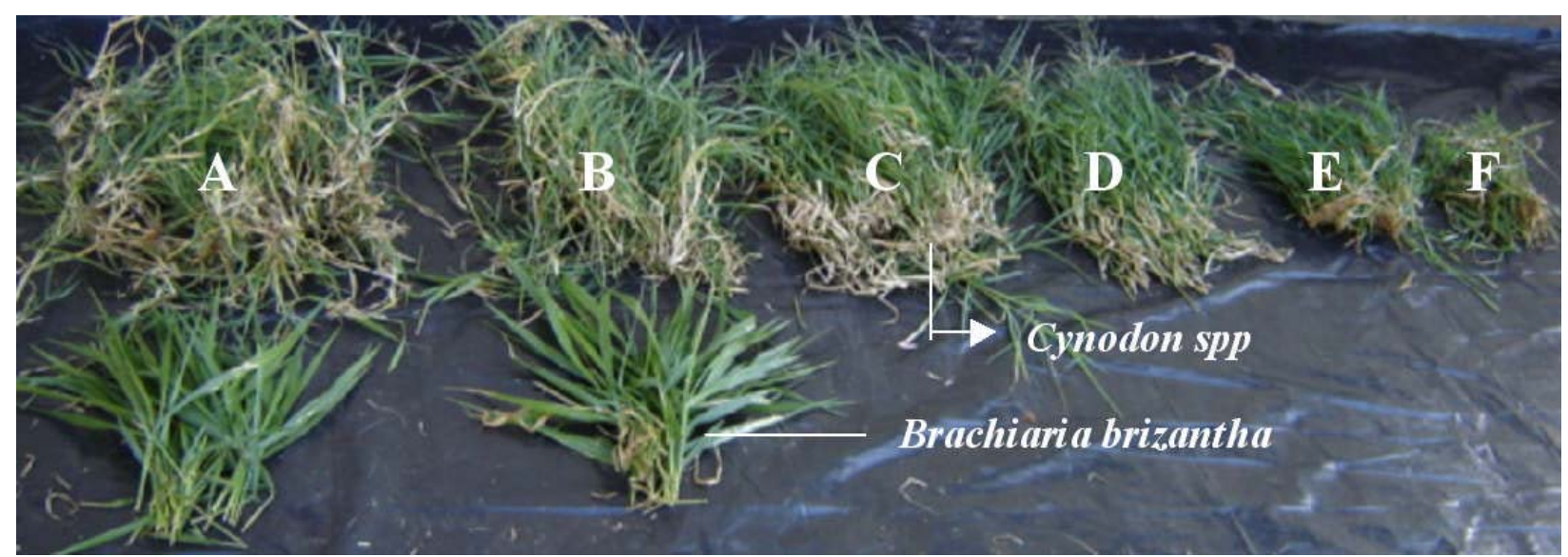

Figura 5 - Matéria verde de plantas de Cynodon spp. (Tifton 85) e Brachiaria brizantha, aos 60 dias após a aplicação (DAA), na primeira época experimental (aplicação antes do perfilhamento da planta de Brachiaria brizantha), para as seguintes doses de glyphosate: testemunha sem herbicida (A); $90 \mathrm{~g} \mathrm{ha}^{-1}$ (B); $180 \mathrm{~g} \mathrm{ha}^{-1}$ (C); $360 \mathrm{~g} \mathrm{ha}^{-1}$ (D); $720 \mathrm{~g} \mathrm{ha}^{-1}$ (E); e $1.080 \mathrm{~g} \mathrm{ha}^{-1}$ (F).

Na Tabela 2, verifica-se que a produção de massa seca de $B$. brizantha, aos 60 DAA, não foi afetada pelo glyphosate até $180 \mathrm{~g} \mathrm{ha}^{-1}$, mas afetou a rebrota, uma vez que a biomassa, aos 60 DAC, foi menor. O glyphosate a partir da dose de $360 \mathrm{~g}_{\text {ha }}{ }^{-1}$ promoveu redução drástica na massa seca de $B$. brizantha aos 60 DAA e total inibição da rebrota aos 60 DAC. Essa eficiência no manejo de $B$. brizanthabeneficiou o crescimento do Tifton 85 , pela eliminação da competição.

Foi observado aos 60 DAA, tanto na aplicação antes do perfilhamento quanto com plantas com quatro a cinco perfilhos, que baixas doses $\left(133,6\right.$ e $365,63 \mathrm{~g} \mathrm{ha}^{-1}$, respectivamente) levam ao controle eficiente de $B$. brizantha, o que é confirmado com a ausência de rebrota dessas plantas a partir das doses de 180 e $360 \mathrm{~g} \mathrm{ha}^{-1}$, aos 60 DAC. Nestas doses, as plantas de Tifton 85 apresentam baixa porcentagem de intoxicação, não influenciando o rendimento dessa forrageira (Tabela 1).

Plantas de Tifton 85 possuem rizomas, que podem estar relacionados à maior tolerância ao glyphosate, servindo como reservas nutritivas e possibilitando sua rebrota. Esse efeito parece estar relacionado à idade da planta, tendo as mais velhas maior tolerância ao herbicida, provavelmente devido à maior quantidade de rizomas, e, assim, maior acúmulo de reservas. Nesse sentido, foi observada, na segunda época, alta capacidade de rebrota das plantas de Tifton 85 mesmo em altas doses do herbicida (1.800 $\left.\mathrm{g} \mathrm{ha}^{-1}\right)$. Acredita-se, segundo Machado (2005), que os rizomas formados pelas plantas de Digitaria insularis são ricos em amido, constituindo uma barreira para translocação do herbicida e fonte de reserva para sobrevivência, permitindo rápida brotação das gemas dos estolões. Tuffi Santos et al. (2004), estudando Commelina diffusa e Commelina benghalensis, verificaram que a tolerância ao herbicida glyphosate era maior em $C$. diffusa em razão da maior quantidade de amido encontrada no caule, quando comparado a $C$. benghalensis.

A determinação da época de aplicação e da dose requerida para que o herbicida exerça controle eficiente da espécie daninha, causando o menor dano possível à cultura, é de suma importância. Aplicações tardias podem ser ineficientes no controle, pela necessidade de doses mais elevadas do herbicida, resultando em maior intoxicação na cultura, e, também, pelo maior periodo de competição exercida pela planta daninha. Dessa forma, os resultados permitiram concluir ser possivel o manejo de $B$. brizantha, na formação de pastagem de Tifton 85, utilizando doses de glyphosate de acordo com a época de aplicação, devido à diferença de sensibilidade entre as duas espécies ao herbicida. 


\section{LITERATURA CITADA}

ALVES, M. J. et al. Rendimento forrageiro e valor nutritivo do capim-tifton 85 sob diferentes doses de nitrogênio, colhido ao atingir 30, 40 e $50 \mathrm{~cm}$ de altura. In: REUNIÃO ANUAL DA SOCIEDADE BRASILEIRA DE ZOOTECNIA, 2001, Piracicaba. Anais... Piracicaba: Escola Superior de Agricultura "Luiz de Queiroz", 2001. CD-ROM

ALVIM, M. J. et al. Avaliação sob pastejo do potencial forrageiro de gramíneas do gênero Cynodon, sob dois níveis de nitrogênio e potássio. R. Bras. Zootec., v .32, n.1, p. 47-54, 2003.

BELLUZZO, C. E .C. et al. Produção e composição do capim tifton 85 (Cynodon spp.) submetido a diferentes níveis de nitrogênio. In: REUNIÃO ANUAL DA SOCIEDADE BRASILEIRA DE ZOOTECNIA, 2002, Recife. Anais... Recife: Universidade Federal Rural de Pernambuco, 2002.

BURTON, G. W.; GATES, R. N.; HILL, G. M. Registration of 'Tifton 85 ' bermudagrass. Crop Sci., v. 33, n. 3, p. $644-645,1993$.

EVANGELISTA, A. R.; REZENDE, A. V.; AMARAL, P. N. C. Produção de feno de gramíneas. In: FORRAGICULTURA E PASTAGENS TEMAS EM EVIDÊNCIA, 2005, Lavras. Anais... . Lavras: Universidade Federal de Lavras, 2005. p. 247-276.

GONÇALVES, G. D. et al. Determinação do consumo, digestibilidade e frações protéicas e de carboidratos do feno de Tifton 85 em diferentes idades de corte. R. Bras. Zootec, v. 32, n. 4, p. 804-813, 2003.

HILL, G. M.; GATES, R. N.; BURTON, G. W. Forage quality and grazing steer performance from Tifton 85 and Tifton 78 bermudagrass pastures. J. Anim. Sci., v. 71, n. 12, p. 3219-3225, 1993.

LORENZI, H. Plantas daninhas do Brasil: terrestres, aquáticas, parasitas e tóxicas. 3.ed. Nova Odessa: Instituto Plantarum, 2000. $339 \mathrm{p}$.

MACHADO, A. F. L. Biologia e controle químico de Digitaria insularis (L.). 2005. 45 f. Dissertação (Mestrado em Fitotecnia) - Universidade Federal de Viçosa, Viçosa, MG, 2005.
OLIVEIRA, M. A. et al. Rendimento e valor nutritivo do capim-tifton 85 (Cynodon spp.) em diferentes idades de rebrota. R. Bras. Zootec., v. 29, n. 6, p. 1949-1960, 2000. (Suplemento, 1).

PEDREIRA, C. G. S. Avaliação de novas gramíneas do gênero Cynodon para a pecuária do sudeste dos Estados Unidos. In: WORKSHOP SOBRE O POTENCIAL FORRAGEIRO DO GENERO CYNODON, 1996, Juiz de Fora. Anais... Juiz de Fora: Embrapa-CNPGL, 1996. p. 111-125.

PEREIRA J. R. P.; SILVA, W. Controle de plantas daninhas em pastagens. (Instrução técnica para o produtor de Leite. Juiz de Fora: EMBRAPA- Juiz de Fora, MG, Dezembro/2000).

ROCHA, G. P.; EVANGELISTA, A. R.; LIMA, J. A. Nitrogênio na produção de matéria seca, teor e rendimento de proteína bruta de gramíneas tropicais. In: REUNIÃO ANUAL DA SOCIEDADE BRASILEIRA DE ZOOTECNIA, 2001, Piracicaba. Anais... Piracicaba: Escola Superior de Agricultura "Luiz de Queiroz", 2001.

ROSA, B. et al. Valor nutritivo dos fenos de soja perene e do capim tifton 85 adubado com diferentes doses de nitrogênio. In: REUNIÃO ANUAL DA SOCIEDADE BRASILEIRA DE ZOOTECNIA, 2002, Recife. Anais... Recife: Universidade Federal Rural de Pernambuco, 2002. CD-ROM

ROVETTA, R. et al. Morfogênese foliar do capim-bermuda 'Tifton 85' sob diferentes doses de nitrogênio, colhido ao atingir 30, 40 e $50 \mathrm{~cm}$ de altura. In: REUNIÃO ANUAL DA SOCIEDADE BRASILEIRA DE ZOOTECNIA, 2001, Piracicaba. Anais... Piracicaba: Escola Superior de Agricultura "Luiz de Queiroz", 2001.

SILVA, A. A.; FERREIRA, F. A.; FERREIRA, L. R. Controle de plantas danihas. Brasília: ABEAS, 2003. 260 p.

SILVA, A. A. et al. Manejo de plantas daninhas. Brasília: ABEAS, 2006. 268 p.

TUFFI SANTOS, L. D. et al. Efeito do glyphosate sobre a morfoanatomia das folhas e do caule de Commelina diffusa e C. benghalensis. Planta Daninha, v. 22, n. 1, p. 101-108, 2004. 